\title{
A Study on the Used of Bluetooth Detectors at a Fix Location for Vehicle Speed Estimation
}

\author{
Way Shyun Neow ${ }^{1}$ and Edwin C.Y. Chung ${ }^{1, *}$ \\ ${ }^{1}$ School of Engineering, Taylor's University, 1 Jln Taylor's, 47500 Subang Jaya, Selangor, Malaysia
}

\begin{abstract}
Usage of Bluetooth for traffic monitoring has been widely researched and well understood. By placing a Bluetooth detector at each end of a segment of a road; the time difference when a Bluetooth device, traveling in a vehicle through that segment, is observed by these detectors is taken to be the time taken by the vehicle to travel along that known segment. The known distance between the detectors and the time it takes to traverse this distance makes it possible to estimate the average speed of the vehicle along that segment. The possibility of estimating the average speed of vehicles within the radio range of a Bluetooth detector, however, has not be carried out until now. The premise of this research is to determine the time a Bluetooth device takes to traverse through the radio range of a detector and from this estimation of the speed of the vehicle traveling through the radio range of the detector. The usage of multiple detectors at the same point to improve the accuracy of the estimates is also investigated. The results of our experiments and what is need to realise such a system are discussed.
\end{abstract}

\section{Introduction}

The ability to determine and disseminating accurate traffic conditions to road users in a timely manner has many advantages. Technology for traffic monitoring is a widelyresearched topic and are based on technologies ranging from image processing, radio technology such as RFID \& Bluetooth to GPS.

A method in image processing is to estimate traffic density through images captured [1]. The disadvantages of this method are that image processing involves complex algorithm and extensive computing infrastructure. RFID, on the other hand, involve the use of RFID sensors placed along a road which is used to detect the RFID attached to the vehicle number plate. The vehicle average speed between any 2 detectors is then estimated based on the time it takes to traverse that section of the road [2]. The main disadvantage of this method is the need to introduce RFID tagging of vehicles. Ahmad et al. [3] indicated that RFID tags can be linked to personal information and may be a barrier to implementation. Bluetooth, on the other hand, is a technology that has lots of potential in traffic monitoring. Nowadays, devices such as car radio, smart phone, laptop and various other gadgets are Bluetooth enabled. Bluetooth is in many ways no different from RFID with the exemption

\footnotetext{
${ }^{*}$ Corresponding author: Edwin.Chung@,taylors.edu.my
} 
that they are already available in vehicles traveling along our roads. It is relatively low costs and has low energy consumption.

Current Bluetooth traffic monitoring systems utilise Bluetooth detector placed at each end of a segment of a road. These detectors will intercept the Media Access Control Identity (MAC ID) of the Bluetooth devices in the vehicle and the average speed of the vehicle travelling through this segment of the road is then estimated based on the time difference a MAC ID was detected at these detectors shown in Fig. 1.

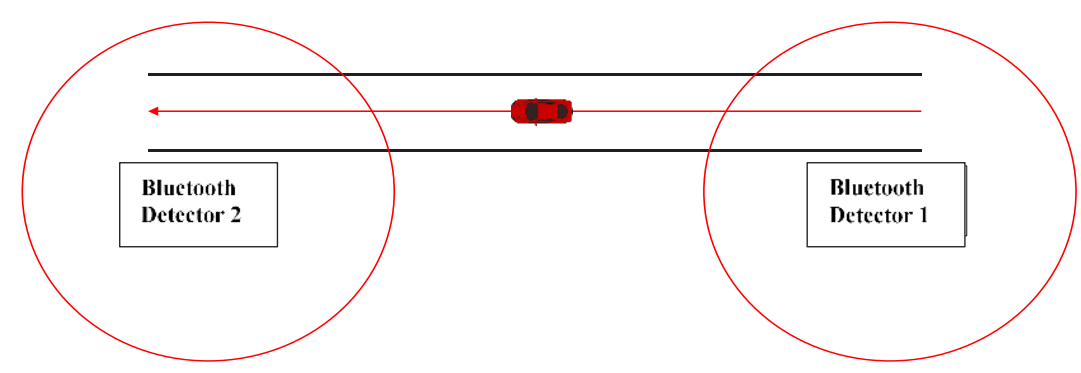

Fig. 1. Two Bluetooth detectors demarking a segment of a road being monitored.

Current research on traffic monitoring using Bluetooth technology are based on this configuration of having two detectors at each end of a segment of a road. There is, thus far, no study on the potential use of one or more Bluetooth detectors at a fix location for the estimation of vehicle speed within the radio range of the detector(s). An advantage of such a system is the reduction in the time difference between the indicated and the actual traffic. It has the potential to be able to determine the traffic condition at a round-about.

\section{Bluetooth inquiry process}

Bluetooth utilises an inquiry process to acquire the MAC ID of other Bluetooth devices within its radio range. During the process, the Bluetooth detector will send an inquiry packet (ID packet) via one of the 32 predefined inquiry channel. Once the vehicle Bluetooth device receive the ID packet, it will send a Frequency Hop Synchronization (FHS) packet back to the detector. Fig. 2. shows the format of a MAC ID[4], [5] consisting of 2, 1 and 3 bytes of non-significant address part (NAP), upper address part (UAP) and lower address part (LAP) respectively.

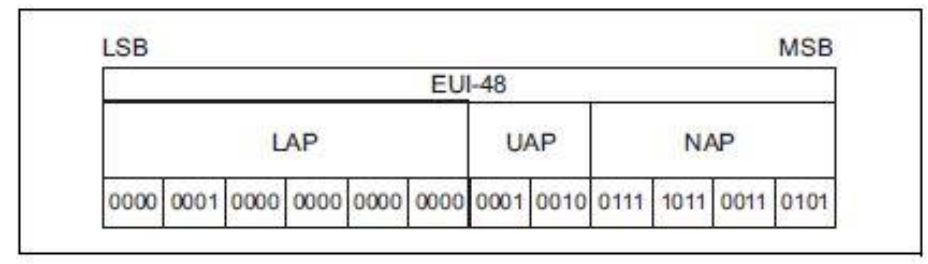

Fig. 2. MAC ID of Bluetooth devices [4].

Bluetooth utilises a frequency hopping spread spectrum technology consisting of 79 frequency channels. Of these, 32 are used as inquiry channels, 16 of these in the A train and the remaining 16 in the B train. At two consecutive $312.5 \mu \mathrm{s}$, the Bluetooth detector will send an ID packet to two inquiry channels and listen for incoming reply at the next two consecutive $321.5 \mu \mathrm{s}$. This is repeated 256 times for each train. In addition, one frequency 
will be changed between the two trains every 1.28s. Fig. 3 shows the Inquiry process [4], $[5]$.

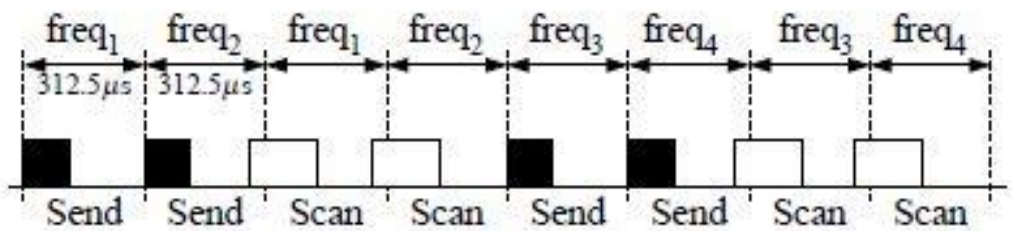

Fig. 3. Bluetooth inquiry process [5].

Franssens et al. [6] conduct research on having multiple Bluetooth inquirers in Bluetooth Discovery Process. The first study is about having multiple Bluetooth detectors present which is able to enhance the discovery of nearby Bluetooth devices. From Fig. 4 shows having 5 inquirers (Bluetooth detectors) perform better than 1 inquirer and 3 inquirers.

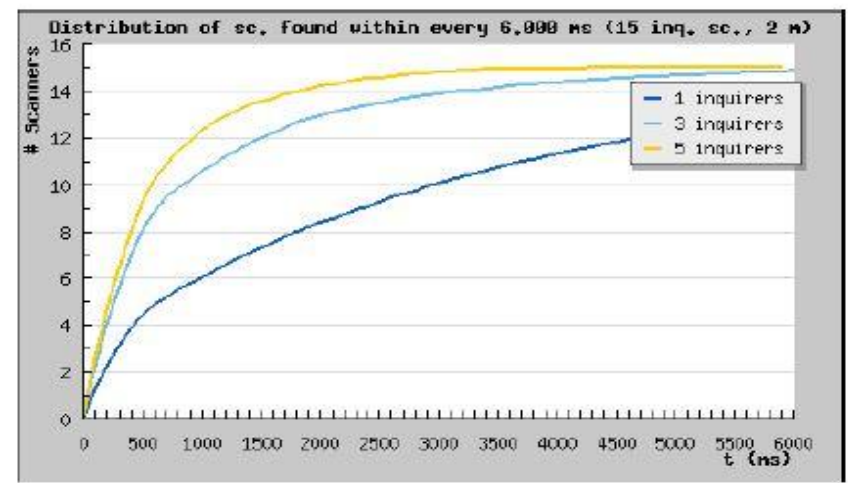

Fig. 4. Comparison of time taken for 1, 3 and 5 inquirers scan to 15 inquiry scanning device.

\section{Design of the Bluetooth detector}

\subsection{Hardware design}

\subsubsection{HC-05 [7]}

The HC-05, a class 2 Bluetooth module with a communication range of approximate 15 meters, is used in this research. The specification of the HC-05 is shown in Tab. 1. The function of pin is shown in Tab. 2.

Tab. 1. HC-05 specification.

\begin{tabular}{|l|c|c|}
\hline \multicolumn{1}{|c|}{ Parameter } & Value & Unit \\
\hline Sensitivity & -80 & $\mathrm{dBm}$ \\
\hline Transmit power & 4 & $\mathrm{dBm}$ \\
\hline Operating voltage & $1.8-3.6$ & $\mathrm{~V}$ \\
\hline
\end{tabular}


Tab. 2. HC-05 pin description and function.

\begin{tabular}{|l|l|l|}
\hline Pin & Description & Function \\
\hline EN & Disable module & Disable module with LOW input \\
\hline$+5 \mathrm{~V}$ & Power supply & Supply voltage to the module \\
\hline GND & Ground & Ground of power source \\
\hline TX & Transmit & Connect to receive of micro-controller \\
\hline RX & Receive & Connect to transmitter of micro-controller \\
\hline STATE & Indication & $\begin{array}{l}\text { To determine if the Bluetooth module is connected. HIGH } \\
\text { when it is connected. LOW when it is not connected }\end{array}$ \\
\hline Pin 34 & Command mode & Provide HIGH (3.3V) input to enter command mode/AT mode \\
\hline
\end{tabular}

\subsubsection{Data logger shield [8]}

An Adafruit data logger shield is used in this research. It has a built-in Real Time Clock (RTC) module and a Secure Digital (SD) card module. The RTC module is used as the system clock and the SD card module is used for storing data. As there is no intention to build a complete system in this research, data collected are only analysed offline, hence the need for an SD card module for data storage.

\subsubsection{Microcontroller development platform [9], [10]}

The Arduino UNO, powered by an ATmega328 microcontroller, is used in this research. The specification of the Arduino UNO is shown in Tab. 3.

Tab. 3. Arduino ATmega $328 \mathrm{MCU}$ specification

\begin{tabular}{|c|c|c|}
\hline \multicolumn{2}{|c|}{ Description } & Arduino Uno \\
\hline \multirow[t]{2}{*}{ Input/output pin } & Digital pin & 14 \\
\hline & Analog pin & 6 \\
\hline \multicolumn{2}{|l|}{ Frequency clock } & $16 \mathrm{MHz}$ \\
\hline \multicolumn{2}{|l|}{ Input power } & $7 \mathrm{~V}-12 \mathrm{~V}$ \\
\hline \multicolumn{2}{|l|}{ Flash memory } & $32 \mathrm{~KB}$ \\
\hline \multicolumn{2}{|l|}{ SRAM } & $2 \mathrm{~KB}$ \\
\hline \multicolumn{2}{|l|}{ EEPROM } & $1 \mathrm{~KB}$ \\
\hline
\end{tabular}

\subsubsection{Power supply}

A breadboard power supply is used to provide a steady voltage source $(5 \mathrm{~V})$ to the components. It also acts as an overcurrent protection for the components. It must be noted that during this research, the Arduino UNO is power through the USB cable connecting it to the laptop and not the breadboard power supply unit. It is observed that the RTC module on data logger shield will malfunction when it is powered using the breadboard power supply. 


\subsubsection{Schematic design}

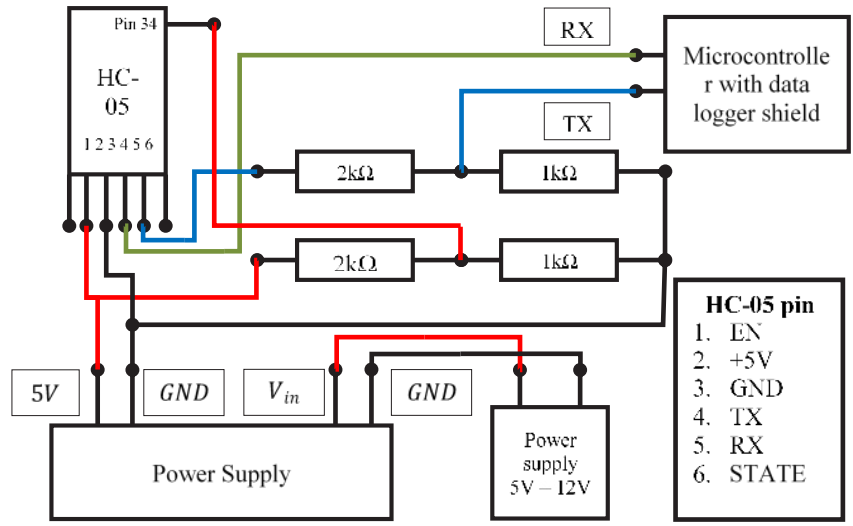

Fig. 5. Schematic diagram of a single Bluetooth detector.

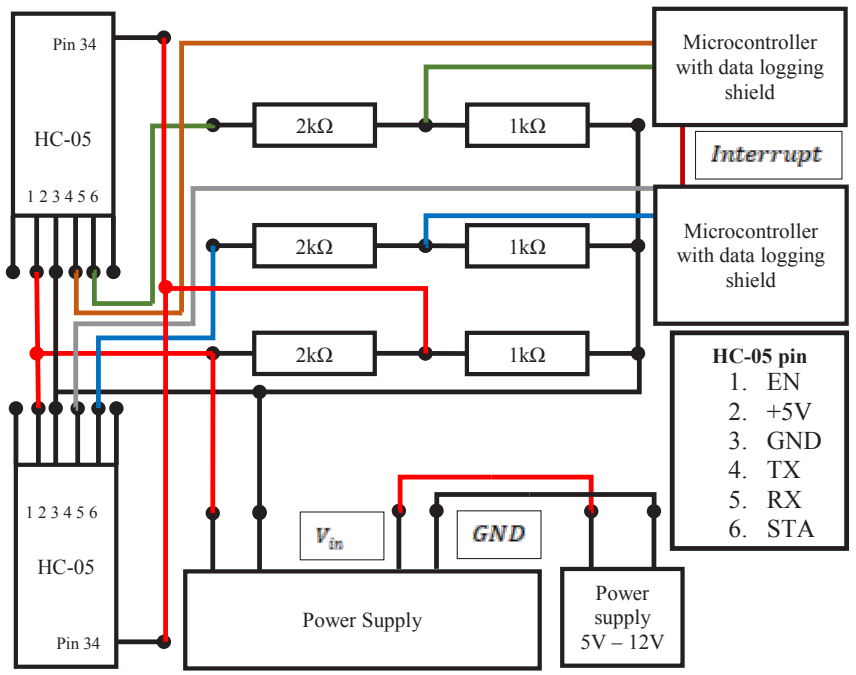

Fig. 6. Schematic diagram of a dual Bluetooth detector.

Tab. 4. Bluetooth module and microcontroller communication.

\begin{tabular}{|c|c|c|c|}
\hline \multicolumn{2}{|c|}{ Bluetooth module } & \multicolumn{2}{c|}{ Microcontroller } \\
\hline Pin 4 & Transmit & Pin 8 & Receive (Assigned) \\
\hline Pin 5 & Receive & Pin 9 & Transmit (Assigned) \\
\hline
\end{tabular}

From the schematic diagrams above, the serial communication between the HC-05 and the UNO is through the transmit and receive pins. The connection between the communication pins are shown in Tab. 4. The UNO will have to assign its transmit and receive pin as activate. The transmit pin of the HC-05 is directly connected to the microcontroller which the microcontroller can treat a $3.3 \mathrm{~V}$ digital signal it as HIGH. In contrast, microcontroller transmitter need to be step down from $5 \mathrm{~V}$ to $3.3 \mathrm{~V}$ as the $\mathrm{HC}-05$ cannot receive signal voltage higher than $3.3 \mathrm{~V}$. The $5 \mathrm{~V}$ signal is step down with using voltage division rule with resistor $(1 \mathrm{k} \Omega$ and $2 \mathrm{k} \Omega$ ). Fig. 5 shows the design of a single Bluetooth detector and Fig. 6 shows the design for a dual Bluetooth detectors. In the dual detector design, one of the UNO plays the role of an initiator and will interrupt the other 
UNO to initiate the start of another inquiry process in the second UNO after a pre-set delay interval. It is via configuration that two independent inquiry sequence can be initiated with a pre-set delay apart. The prototype as shown in Fig. 7 is built according to design in Fig. 6. One of the Bluetooth detector is switched off for a single detector configuration during testing.

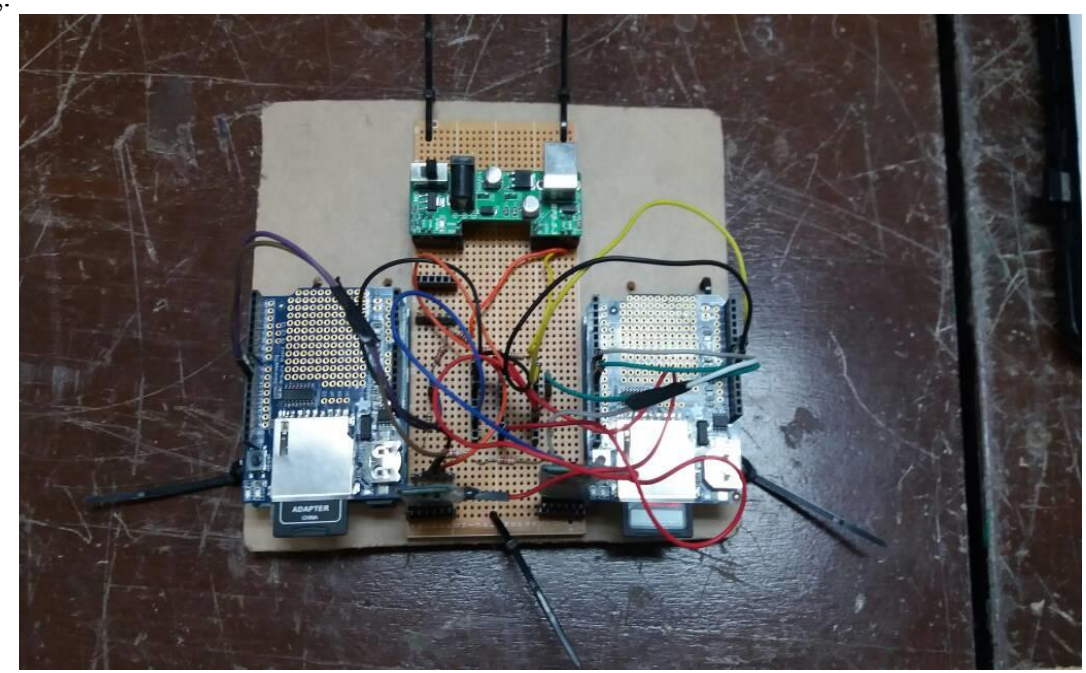

Fig. 7. Prototype.

\subsection{Software design}

\subsubsection{Flow chart}

The functionality of the software embedded in the UNO is as detailed in the flowchart in Fig. 8. For ease of readability, the AT command detailed in this flowchart is summarised in Tab. 5. The reference to ' $a$ ' in the flowchart refers to a variable which record the return value from the Bluetooth module. 


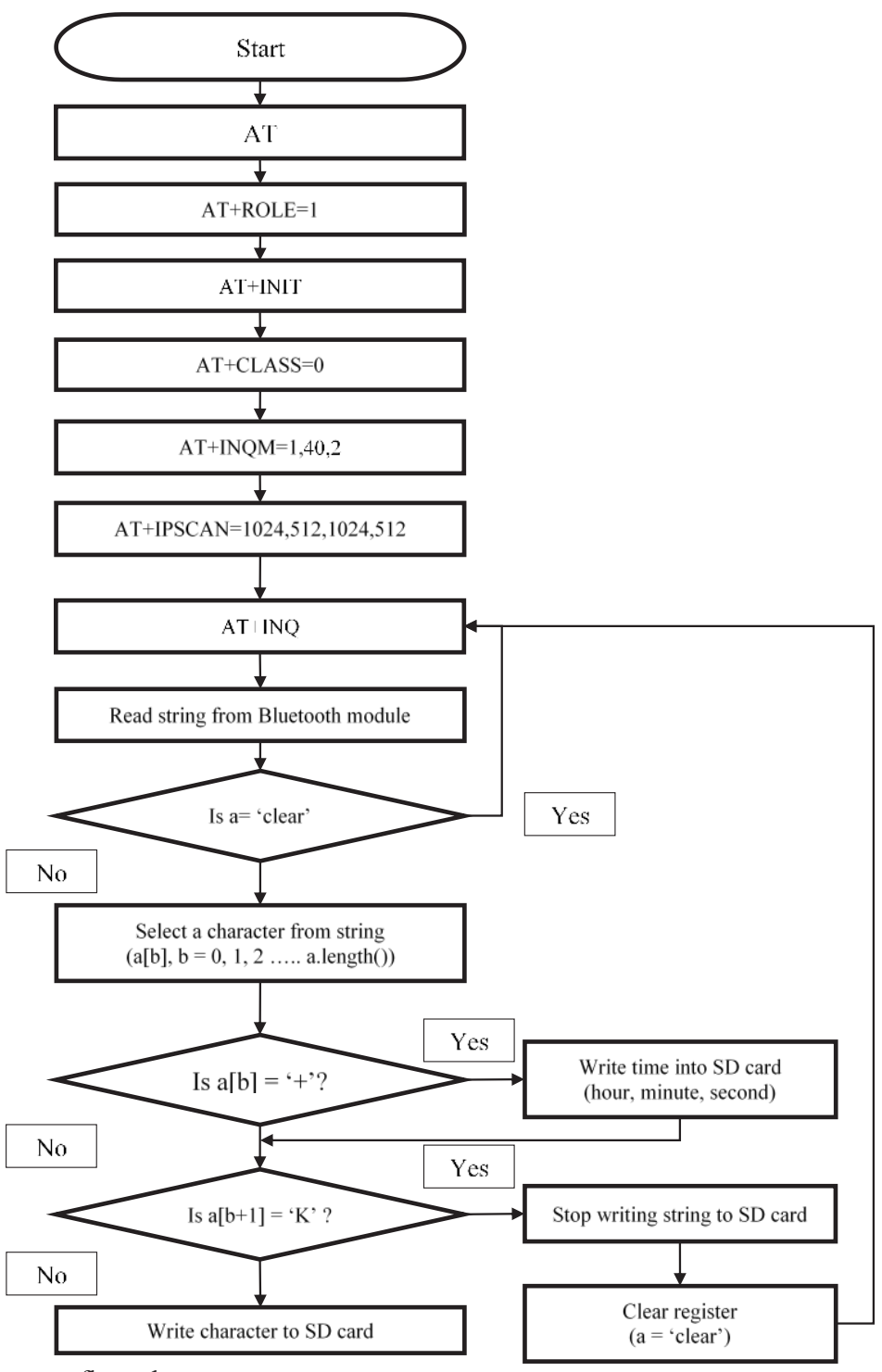

Fig. 8. Program flow chart

\subsubsection{Bluetooth detector AT command explain [7]}

Tab. 5. AT commands.

\begin{tabular}{|l|l|}
\hline AT & $\begin{array}{l}\text { A test command. A response "OK } \backslash r \mid n " \text { is received if the } \\
\text { Bluetooth module is operating properly. }\end{array}$ \\
\hline AT+ROLE= $<$ Param $>$ & $\begin{array}{l}\text { Set the Blutooth module mode. }<\text { Param }>\text { has the value 0, 1 } \\
\text { or 2 for Slave, Master and Slave-Loop mode respectively. }\end{array}$ \\
\hline AT+INIT & $\begin{array}{l}\text { Initialise the SPP profile library. It returns an "OK } \backslash r \mid n " \text { if } \\
\text { the command is executed successfully. }\end{array}$ \\
\hline $\begin{array}{l}\text { AT+CLASS=<Param }> \\
\text { AT+CLASS? }\end{array}$ & $\begin{array}{l}\text { Set/Inquire device class. When setting the device class, } \\
<\text { Param }>\text { is set to the value 0 for default class. }\end{array}$ \\
\hline
\end{tabular}




\begin{tabular}{|c|c|}
\hline $\begin{array}{l}\text { AT+INQM }=<\text { Param1 }>, \\
<\text { Param2 }>,<\text { Param3 }> \\
\text { AT+INQM? }\end{array}$ & $\begin{array}{l}\text { Set/Inquire Query access patterns. It returns an "OK } \backslash \mathrm{r} \backslash \mathrm{n} \text { " if } \\
\text { the command is executed successfully. } \\
<\text { Param } 1>=0 \text { for inquiry_mode_standard or } 1 \text { for } \\
\text { inquiry_mode_rssi } \\
<\text { Param } 2>=\text { maximum number of Bluetooth devices to } \\
\text { respond to } \\
<\text { Param3 }>\text { maximum of limited inquiring time with value } \\
\text { ranging from } 1 \text { to } 48 \text { corresponding to } 1.28 \text { s to } 61.44 \mathrm{~s} \text {. }\end{array}$ \\
\hline $\begin{array}{l}\text { AT+IPSCAN }=<\text { Param1 }>\text {, } \\
<\text { Param2 }>,<\text { Param3 }>, \\
<\text { Param } 4> \\
\text { AT+IPSCAN? }\end{array}$ & $\begin{array}{l}\text { Set/Inquire scan parameter. It returns an "OK } \backslash \mathrm{r} \backslash \mathrm{n} \text { " if the } \\
\text { command is executed successfully. } \\
<\text { Param } 1>=\text { Query time interval } \\
<\text { Param2 }>=\text { Query duration } \\
<\text { Param3 }>=\text { Paging interval } \\
<\text { Param } 4>=\text { Call duration } \\
\text { Default values: } 1024,512,1024,512\end{array}$ \\
\hline $\mathrm{AT}+\mathrm{INQ}$ & $\begin{array}{l}\text { Inquire Bluetooth device with the radio range. It returns } \\
+ \text { INQ: }<\text { Param } 1>,<\text { Param } 2>,<\text { Param } 3> \\
\ldots \\
\text { OK } \\
\text { Where }<\text { Param } 1>\text { is the Bluetooth address, }<\text { Param } 2>\text { the } \\
\text { device type and }<\text { Param } 3>\text { the RSSI signal intensity. }\end{array}$ \\
\hline
\end{tabular}

\section{Prototype testing}

\subsection{Static test}

The objective is to identify the maximum detecting range of the Bluetooth detector. Furthermore, to justify that class 2 Bluetooth module have a detection range of 15 meters radius. This static test is conducted by having a smart phone with Bluetooth enable being placed at a known distance away from the Bluetooth detector. In the initial test, the smart phone was placed 10 meters away from the Bluetooth detector. Subsequent data points were taken with the distance between the smart phone and the detector increased in increment of 10 meters. This test is repeated until the Bluetooth detector is unable to detect the smart phone. The setting of the experiment is as shown in Fig. 9. Each test will last for 1 minute as the Bluetooth detector is activated. A total of 5 test is conducted for each distance. The setting of the Bluetooth detector inquiry parameters is $\mathrm{AT}+\mathrm{INQM}=1,1,1$ throughout the test. Other than a smart phone, this static test was also conducted with a car Bluetooth enabled radio. 


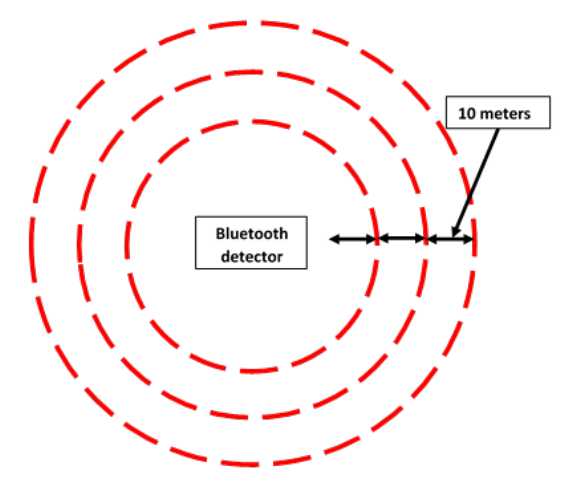

Fig. 9. Static test

\subsection{Dynamic test}

The purpose of the dynamic test is to collect data from the Bluetooth detector so as to determine its ability to estimate the speed of the moving Bluetooth device as well as to evaluate its performance. The test cases are as shown in Tab. 6. Starting from the maximum radio range of the detector (determined from the static test), a Bluetooth device used in the test is moved in a straight line to the opposite side of the radio range as shown in Fig. 10. Data collected from the different scenarios are then compared to determine what is the best configuration for this system.

In order to provide some insight into the test cases detailed in Tab. 7, the objectives of these test cases are described in the following sub-sections.

Tab. 6. Dynamic test cases.

\begin{tabular}{|c|c|c|c|c|c|c|c|c|c|}
\hline \multirow{2}{*}{\multicolumn{2}{|c|}{$\begin{array}{c}\begin{array}{c}\text { Bluetooth module in } \\
\text { detector }\end{array} \\
\begin{array}{c}\text { Bluetooth device } \\
\text { traveling }\end{array}\end{array}$}} & \multicolumn{2}{|c|}{1} & \multicolumn{2}{|c|}{2} & \multicolumn{2}{|c|}{2} & \multicolumn{2}{|c|}{2} \\
\hline & & 1 & 2 & 1 & 2 & 1 & 2 & 1 & 2 \\
\hline \multicolumn{2}{|c|}{ Delay } & & & \multicolumn{2}{|c|}{ No delay } & \multicolumn{2}{|c|}{$\begin{array}{c}\text { Delay by half of } \\
\text { total inquiring } \\
\text { time }\end{array}$} & \multicolumn{2}{|c|}{$\begin{array}{l}\text { Delay by the } \\
\text { total inquiring } \\
\text { time }\end{array}$} \\
\hline \multirow{3}{*}{$\begin{array}{c}\text { Inquiry } \\
\text { parameter }\end{array}$} & $1,1,1$ & $\sqrt{ }$ & $\sqrt{ }$ & $\sqrt{ }$ & & $\sqrt{ }$ & & & \\
\hline & $1,1,2$ & $\sqrt{ }$ & & & & & & $\sqrt{ }$ & \\
\hline & $1,40,4$ & & & & & $\sqrt{ }$ & $\sqrt{ }$ & & \\
\hline
\end{tabular}

\subsubsection{Effect of inquiry time}

The effect of inquiry time on the performance of the Bluetooth detector is conducted by varying the maximum inquiry time limit, $<$ Param $3>$ of the AT + INQM command, between $1.28 \mathrm{~s}$ and $2.56 \mathrm{~s}$. Accordingly, the 2 experimental runs were conducted using the following query settings

- $\quad \mathrm{AT}+\mathrm{INQM}=1,1,1$

- $\mathrm{AT}+\mathrm{INQM}=1,1,2$ 
4.2.2 Effect of multiple Bluetooth detectors with different query settings and delay between their inquiry cycles

The effect of the various query settings (the same settings will be used on both detectors) and the time difference between the inquiry cycle of the 2 detectors as well as the impact on the performance of the detector was conducted. The query settings for the 2 detectors and the delay used were as follows. The delay between the 2 inquiry cycles is necessary to avoid collision.

- $\mathrm{AT}+\mathrm{INQM}=1,1,1$

- $\quad \mathrm{AT}+\mathrm{INQM}=1,10,1$

- $\quad \mathrm{AT}+\mathrm{INQM}=1,1,1$

- $\mathrm{AT}+\mathrm{INQM}=1,1,2$

- $\mathrm{AT}+\mathrm{INQM}=1,40,4$ with no delay

with 5000 milliseconds delay

with 0.64 second delay

with 2.56 second delay

with 2.56 second delay

\subsubsection{Effect of multiple moving Bluetooth devices}

The purpose of these tests is to study the performance of the system where multiple Bluetooth devices are traversing across the radio range of the detector. Two smart phones are used in these experiments and the following settings were used.

- $\mathrm{AT}+\mathrm{INQM}=1,1,1 \quad$ with a single detector

- $\mathrm{AT}+\mathrm{INQM}=1,40,4 \quad$ with 2 detectors $\& 2.56$ s gap between their inquiry cycles

The purpose of the experiment with the AT+INQM=1, 40, 4 settings and a 2.56s delay between the 2 inquiry cycles is for confirmation that it this would all the scanning of the 2 trains of 16 frequency channels concurrently.

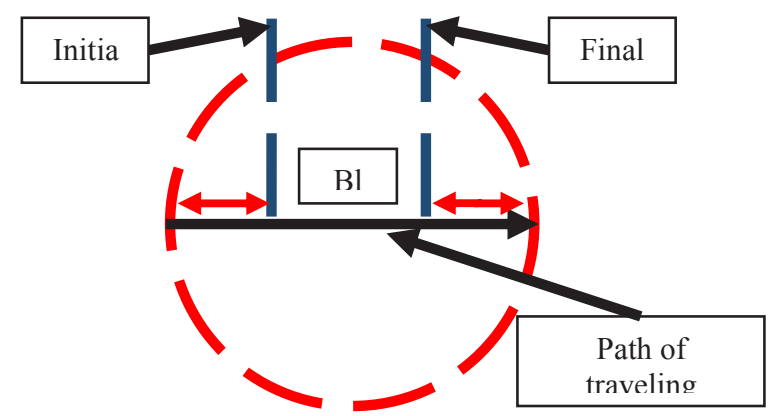

Fig. 10. Dynamic test.

In the dynamic test experiments, the average speed of a Bluetooth device traversing though the radio range of the detector is measure by taking the time it takes $(t)$ to move across a known distance $(s)$ using a stopwatch. The actual average speed is then computed using Equation (1).

$$
v_{\text {aviactual }}=\frac{s}{\mathrm{t}}
$$

The duration a Bluetooth device is within the radio range of a detector can be determine from final time it was detected by the detector, $t_{\text {final }}$, and the time it was initially detected by the detector, $t_{\text {initial. }}$. The predict average speed that is then calculated with Equation (2). 
In this research, the known distance, $s$ in Equation (2), is taken to be 2 times the radio range of the detector.

$$
v_{\text {avipredict }}=\frac{s}{\text { tfinal }^{-t_{\text {initial }}}}
$$

The performance of the system is then analysed by plotting the predicted average speed versus its actual average speed. As one would expect, a perfectly accurate system will produce a straight-line plot where the predicted speed equals the actual speed. As it is not plausible that that a Bluetooth device is detected the very moment it enters the radio range of the detector nor would its last detection be right at the edge as it was about to leave the radio range of the detector, the actual distance traversed by the device is a value smaller than s. As such, even if the detector is working perfectly, the predicted average speed is expected to be higher than the actual average speed. In other words, a plot of the predicted average speed versus the actual speed of a functioning system will produce a line above and parallel to the results for a perfectly accurate system. The more accurate the functional system is, the closer its plot will be to that for the perfect system.

\section{Result}

\subsection{Static test}

\subsubsection{First test}

The target device for this test are car Bluetooth radio and smart phone. Initial static test is conducted with car Bluetooth radio. The result is shown in Tab. 7.

Tab. 7. Static test with car Bluetooth radio detection.

\begin{tabular}{|c|c|c|c|c|c|c|}
\hline \multirow{3}{*}{ Distance $(\mathrm{m})$} & \multicolumn{3}{|c|}{ Trial 1} & \multicolumn{3}{|c|}{ Trial 2} \\
\hline & \multicolumn{2}{|c|}{ Time } & \multirow[b]{2}{*}{ Sample } & \multicolumn{2}{|c|}{ Time } & \multirow[b]{2}{*}{ Sample } \\
\hline & Start time & End time & & Start time & End time & \\
\hline \multirow{2}{*}{2} & $15: 01: 40$ & 15:02:40 & \multirow{2}{*}{7} & $15: 09: 40$ & 15:10:40 & \multirow{2}{*}{7} \\
\hline & 15:01:58 & 15:02:05 & & 15:09:49 & 15:10:00 & \\
\hline \multirow{2}{*}{1} & $15: 24: 50$ & $15: 25: 50$ & \multirow{2}{*}{11} & \multirow{2}{*}{\multicolumn{3}{|c|}{ - }} \\
\hline & $15: 25: 04$ & $15: 25: 12$ & & & & \\
\hline
\end{tabular}

From the initial static test results, it noted that car radio Bluetooth can only be detected over a very short distance and the samples taken are low even though the HC-05 is able to detect a smartphone Bluetooth signal over a much longer range.

\subsubsection{Second test}

The second static test was conducted with a smartphone over a range from $10 \mathrm{~m}$ up to $40 \mathrm{~m}$ in increment of $10 \mathrm{~m}$. At each distance, a total of five tests were conducted with each test running for one minute. However, from the results of these tests, it was noticed that the first detection occurs approximate 14 seconds after powering up. The $14 \mathrm{~s}$ delay is most likely due to coding and hardware design that can be compensated for in a proper implementation. Tab. 8 below shows the results of these experiments. Noticed that the number of detection within the one minute decreases as the distance between the device and the detector increases. 
Tab. 8. Static test with smart phone Bluetooth.

\begin{tabular}{|c|c|c|c|}
\hline Distance (m) & Sample & Duration (s) & $\begin{array}{c}\text { Average time per } \\
\text { sample (s) }\end{array}$ \\
\hline \multirow{4}{*}{10} & 25 & 46 & 1.840 \\
\cline { 2 - 4 } & 17 & 46 & 2.706 \\
\cline { 2 - 4 } & 37 & 46 & 1.243 \\
\cline { 2 - 4 } & 35 & 46 & 1.314 \\
\hline \multirow{4}{*}{20} & 34 & 46 & 1.353 \\
\cline { 2 - 4 } & 19 & 46 & 2.421 \\
\cline { 2 - 4 } & 17 & 46 & 2.706 \\
\cline { 2 - 4 } & 26 & 46 & 1.769 \\
\cline { 2 - 4 } & 20 & 46 & 2.300 \\
\hline \multirow{4}{*}{30} & 13 & 46 & 3.538 \\
\cline { 2 - 4 } & 21 & 46 & 2.190 \\
\cline { 2 - 4 } & 17 & 46 & 2.706 \\
\cline { 2 - 4 } & 16 & 46 & 2.875 \\
\cline { 2 - 4 } & 18 & 46 & 2.556 \\
\cline { 2 - 4 } & 19 & 46 & 2.421 \\
\cline { 2 - 4 } & 2 & 46 & 23.000 \\
\cline { 2 - 4 } & 0 & 46 & - \\
\cline { 2 - 4 } & 1 & 46 & 46.000 \\
\hline \multirow{4}{*}{40} & 1 & 46 & 46.000 \\
\hline
\end{tabular}

\subsection{Dynamic test}

\subsubsection{The effect of increasing inquiry time}

The effect of inquiry time is examined by running the dynamic test, first with the detector settings using "AT+INQM=1, 1, 1" and subsequently using "AT+INQM=1, 1, 2." The resultant predicted average speed for both these settings are as shown in Fig. 11. The first observation from this result is that the accuracy of the predicted average speed decreases as the traveling speed increases. A longer inquiry time is generally more accurate as the detector has a higher chance of detecting the device within its radio range. 


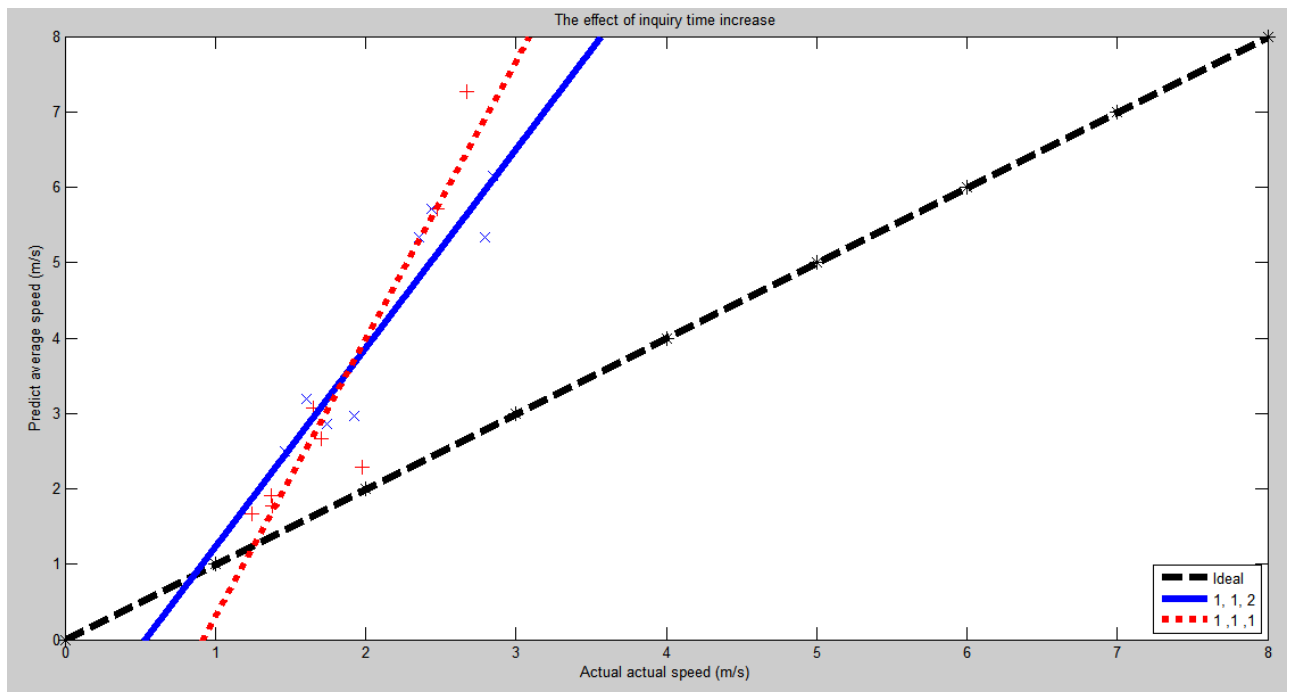

Fig. 11. The effect of increasing inquiry time.

\subsubsection{The impact of having two Bluetooth detectors}

The results for the experiment using two detectors is summarised in Fig. 13. Of the 5 settings, $\mathrm{AT}+\mathrm{INQM}=1,10,1$ with a 5 -millisecond delay between the inquiry cycles of the 2 detectors has the worst performance. Raw data for this experiment seems to shows an anomaly where the Bluetooth module with a delay inquiry sequence received more FHS packets than the ID packets it sends out. Note that a 5-millisecond delay between the 2 inquiry sequences would have the 2 Bluetooth modules only shift the inquiry sequence by half a train as shown in Fig. 12.

\begin{tabular}{l}
\multicolumn{10}{|c|}{ Delay 5000 micro-seconds } \\
$\qquad$\begin{tabular}{|l|l|l|l|l|l|l|l|l|l|l|l|l|l|l|l|l|}
\hline 1 & 1 & 2 & 3 & 4 & 5 & 6 & 7 & 8 \\
\hline 1 & 2 & 3 & 4 & 5 & 6 & 7 & 8 & 9 & 10 & 11 & 12 & 13 & 14 & 15 & 16 \\
\hline
\end{tabular}
\end{tabular}

Fig. 12. AT $+\mathrm{INQM}=1,10,1$ with a delay by 5 -millisecond delay between the 2 inquiry-sequence.

The results in Fig. 13 shows that the AT+INQM=1,1,1 query setting with no delay ${ }^{\dagger}$ seems to have the best performance. The results as shown in Tab. 10 shows the Bluetooth module with the leading inquiry sequence is able to capture more data. The additional data provided by the other Bluetooth module was found to not be able to improve the accuracy of the speed estimation.

In these experiments, $\mathrm{AT}+\mathrm{INQM}=1,40,4$ with a delay of $2.56 \mathrm{~s}$ was found to have three extreme data as detailed in Tab. 9. The removal of these extreme data points would produce a result as shown in Fig. 14. This lead us to belief that there exists a possibility of a

\footnotetext{
$\dagger$ It is important to note that though no delay is set, the execution of the command by the microcontroller will inherently introduce a delay between the 2 inquiry sequences.
} 
way to improve the predicted average speed if we could find a way to exclude such extreme data points.

Tab. 9. Extreme data from $\mathrm{AT}+\mathrm{INQM}=1,40,4 \&$ a delay of $2.56 \mathrm{~s}$ between sequence

\begin{tabular}{|c|c|}
\hline $\begin{array}{c}\text { Actual average } \\
\text { traveling speed }\end{array}$ & $\begin{array}{c}\text { Predict average } \\
\text { traveling speed }\end{array}$ \\
\hline 1.83 & 6.15 \\
\hline 2.88 & 10.00 \\
\hline 2.96 & 16.00 \\
\hline
\end{tabular}

Tab. 10. Setting of $\mathrm{AT}+\mathrm{INQM}=1,1,1$ with no delay between the 2 inquiry-sequence.

\begin{tabular}{|c|c|c|c|c|c|c|c|c|}
\hline \multicolumn{3}{|c|}{ Average speed with stopwatch } & \multicolumn{3}{|c|}{$\begin{array}{l}\text { Average speed with Bluetooth } \\
\text { Detector }\end{array}$} & \multirow{2}{*}{\multicolumn{3}{|c|}{$\begin{array}{l}\text { Number of samples } \\
\text { collected by Bluetooth } \\
\text { module with leading and } \\
\text { lagging inquiry sequence }\end{array}$}} \\
\hline \multirow{2}{*}{$\begin{array}{l}\text { Distance } \\
\text { (m) }\end{array}$} & \multirow{2}{*}{$\begin{array}{l}\text { Time } \\
(\mathrm{s})\end{array}$} & \multirow{2}{*}{$\begin{array}{l}\text { Speed } \\
(\mathrm{m} / \mathrm{s})\end{array}$} & \multirow{2}{*}{$\begin{array}{l}\text { Distance } \\
(\mathrm{m})\end{array}$} & \multirow{2}{*}{$\begin{array}{l}\text { Duration } \\
\text { (s) }\end{array}$} & \multirow{2}{*}{$\begin{array}{l}\text { Speed } \\
(\mathrm{m} / \mathrm{s})\end{array}$} & & & \\
\hline & & & & & & Leading & lagging & total \\
\hline 20 & 24.88 & 0.80 & 20 & 10 & 2.00 & 6 & 0 & 6 \\
\hline 20 & 23.72 & 0.84 & 20 & 19 & 1.05 & 14 & 1 & 15 \\
\hline 20 & 23.00 & 0.87 & 20 & 13 & 1.54 & 15 & 4 & 19 \\
\hline 20 & 20.78 & 0.96 & 20 & 16 & 1.25 & 6 & 4 & 10 \\
\hline 20 & 18.12 & 1.10 & 20 & 13 & 1.54 & 9 & 3 & 12 \\
\hline 20 & 13.05 & 1.53 & 20 & 4 & 5.00 & 6 & 1 & 7 \\
\hline 20 & 11.16 & 1.79 & 20 & 11 & 1.82 & 9 & 1 & 10 \\
\hline
\end{tabular}

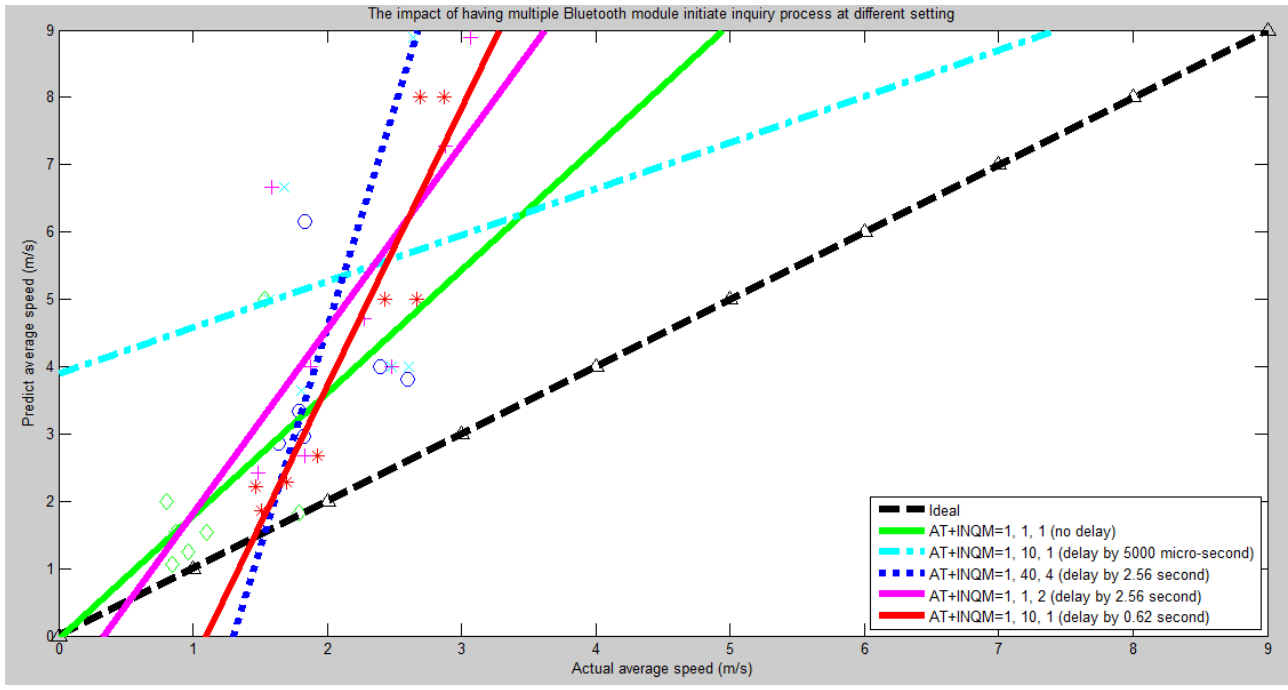

Fig. 13. The impact of having multiple Bluetooth module initiate inquiry process at different setting 


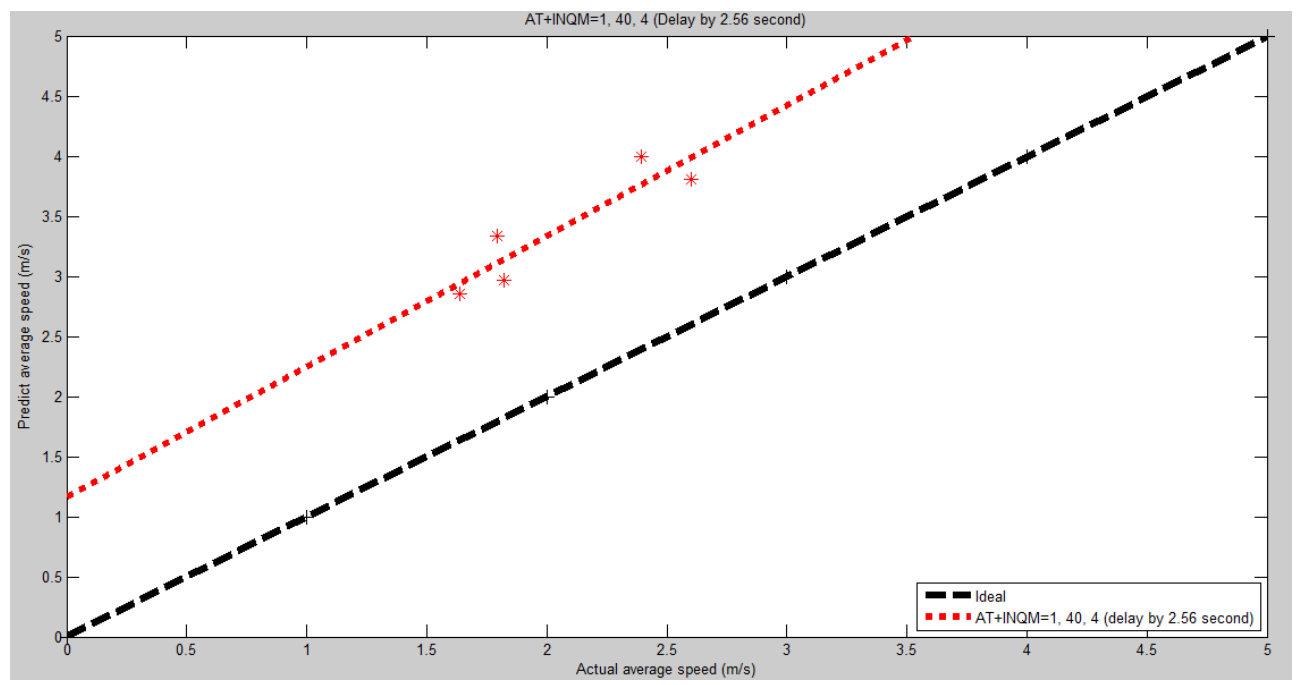

Fig. 14. $A T+I N Q M=1,40,4$ with extreme data points removed.

\subsubsection{The impact of having multiple traveling Bluetooth device}

Comparing Fig. 16 and Fig. 17 it is observed that a single Bluetooth detector with a AT+INQM=1,1,1 setting performs poorly as compared to a configuration with 2 Bluetooth detectors with a AT+INQM=1,40,4 setting and a $2.56 \mathrm{~s}$ delay. The single detector configuration even fail to detect one of the device in a number of trials. The single Bluetooth detector is also unable to pick up sufficient data to determine the traveling speed of the device. On the other hand, a 2 Bluetooth module configuration with a $\mathrm{AT}+\mathrm{INQM}=1,40,4$ settings and a $2.56 \mathrm{~s}$ delay between their inquiry sequence is able to pick up sufficient data to determine the average speed of both devices. This shows that with proper delay, the Bluetooth detector is able perform well with two Bluetooth modules. By allowing the two Bluetooth modules to scan at different frequency train at the same time increases the efficiency of the Bluetooth detector. The scanning sequence of the Bluetooth detector is with a 2.56 s delay is as shown in Fig. 15.

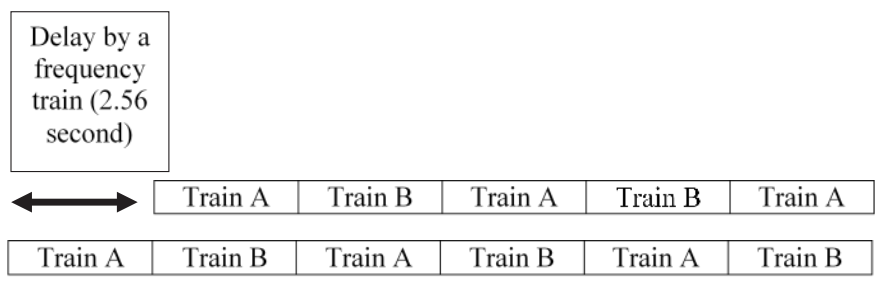

Fig. 15. Inquiry sequence with a 2.56 second delay between them. 


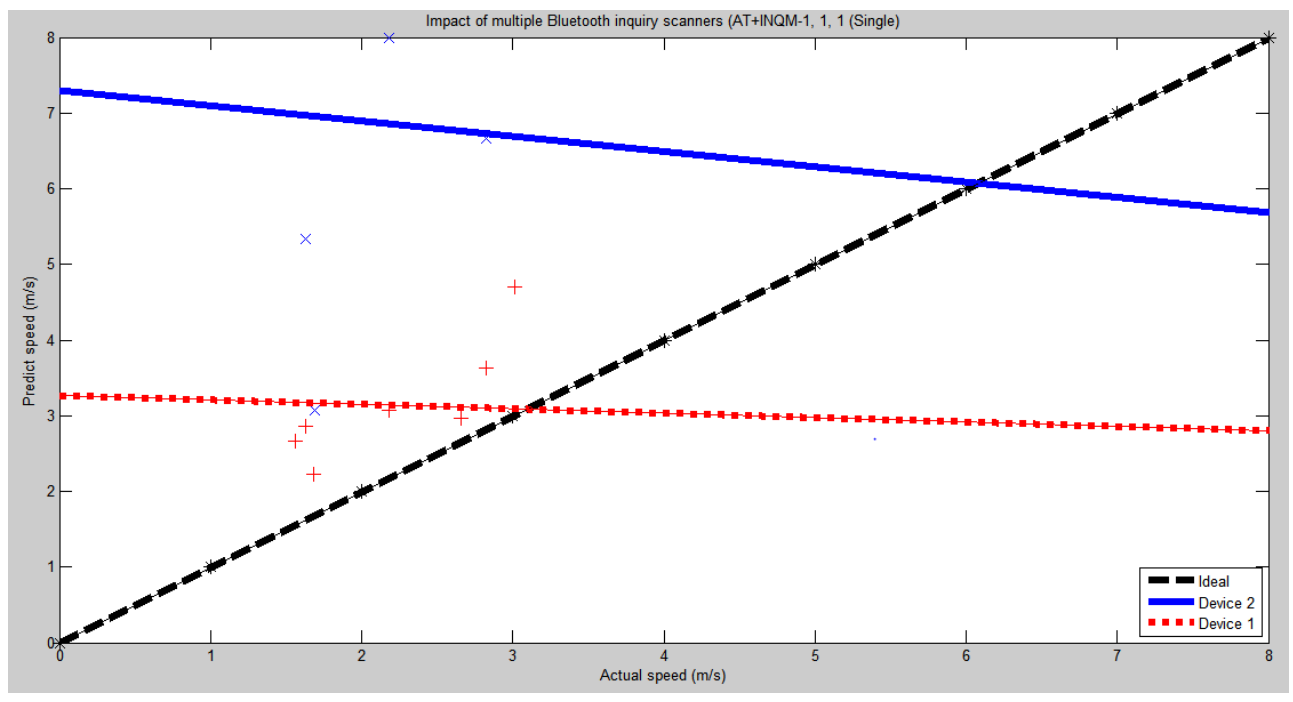

Fig. 16. Impact of two Bluetooth devices on a detector using a single Bluetooth module and a query setting of $\mathrm{AT}+\mathrm{INQM}=1,1,1$

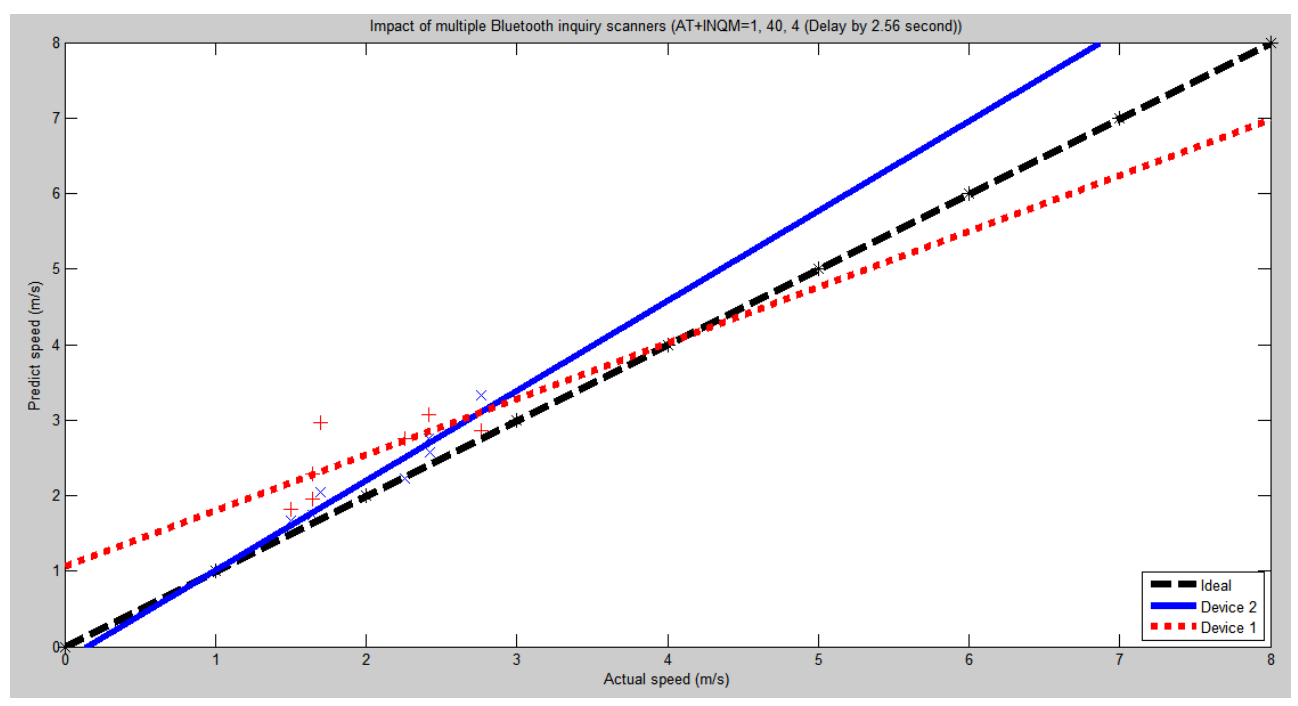

Fig. 17. Impact of two Bluetooth devices on a detector with 2 Bluetooth modules and a query setting of $\mathrm{AT}+\mathrm{INQM}=1,40,4$ and a 2.56 s delay between the inquiry sequence.

\section{Conclusion}

Bluetooth traffic monitoring systems has advantages but there are challenges to overcome. The first challenge would be the detection range. Bluetooth detectors will have different detection range depending on the Bluetooth devices it is trying to detect. Furthermore, the power class of traveling Bluetooth device will have effect on the detection range of Bluetooth detectors. From the first dynamic test, it shows that having longer scanning time, the Bluetooth detector has higher chance of detecting device at further distance. The second dynamic test result shows that inquiry parameter $\mathrm{AT}+\mathrm{INQM}=1,40,4$ have better speed estimation compare to other setting when extreme data is removed. At the last dynamic test, 
it shows that with proper delay and setting, having two Bluetooth modules can outperform a single Bluetooth detector. From the dynamic test, it proves that having more Bluetooth detectors at a fix point has a better speed estimation compare to a single Bluetooth detector. However, the challenge is to avoid frequency channel interference between the two devices.

\section{References}

[1] P. Khanke and P. P. S. Kulkarni, "A Technique on Road Traffic Analysis using Image Processing,” Int. J. Eng. Res. Technol., vol. 3, no. 2, pp. 2769-2772, (2014).

[2] F. Aloul, A. Sagahyroon, A. Nahle, M. A. Dehn, and R. Al Anani, "GuideME : An Effective RFID-Based Traffic Monitoring System," in IASTED International Conference, (2012), pp. 353-359.

[3] S. Ahmad, R. Lu, and M. Ziaullah, "Bluetooth an Optimal Solution for Personal Asset Tracking: A Comparison of Bluetooth, RFID and Miscellaneous Anti-lost Traking Technologies," Int. J. u- e-Serv. Sci. Technol., vol. 8, no. 3, pp. 179-188, (2015).

[4] Bluetooth SIG Proprietary, "Bluetooth Core Specification Master Table of Contents \& Compliance Requirements," Bluetooth SIG, (2016). [Online]. Available: https://www.bluetooth.com/specifications/bluetooth-core-specification.

[5] M. Duflot, M. Kwiatkowska, G. Norman, and D. Parker, "A Formal Analysis of Bluetooth Device Discovery," Int. J. Softw. Tools Technol. Transf., vol. 8, no. 6, pp. 621-632, (2006).

[6] A. Franssens, "Impact of multiple inquires on the bluetooth discovery process : and its application to localization," UNIVERSITY OF TWENTE, (2010).

[7] Itead Studio, "HC-05 User's Manual," (2010). [Online]. Available: http://www.electronicaestudio.com/docs/istd016A.pdf.

[8] B. E. Last and P. M. Utc, "Adafruit Data Logger Shield," Adafruit Industries, (2017). [Online]. Available: https://cdn-learn.adafruit.com/downloads/pdf/adafruitdata-logger-shield.pdf.

[9] Arduino, “ARDUINO PRO," (2017). [Online]. Available: https://store.arduino.cc/usa/arduino-pro.

[10] J. C. Quer, “Arduino UNO datasheet," (2014). [Online]. Available: datasheet.octopart.com/A000066-Arduino-datasheet-38879526.pdf. 